\title{
The fate and behavior of selected endocrine disrupting chemicals in full scale wastewater and sludge treatment unit processes
}

\author{
A. O. Ifelebuegu \\ Department of Geography, Environment and Disaster Management, Coventry University, Coventry, CV1 5FB, \\ United Kingdom \\ Received 10 August 2010; revised 14 November 2010; accepted 21 January 2011; available online 1 March 2011
}

\begin{abstract}
Endocrine disrupting chemicals are discharged into the environment mainly through wastewater treatment processes. There is a need for better understanding of the fate of these compounds in the unit processes of treatment plant to optimise their removal. The fate of oestrone, 17 $\beta$-estradiol, $17 \alpha$-ethinyestradiol and nonylphenol in the unit processes of full scale wastewater treatment plants in the UK, including activated sludge plant, oxidation ditch, biofilter and rotating biological contactor were investigated. The overall removal efficiencies of all the compounds ranged from $41 \%$ to $100 \%$. The removals were predominantly during the secondary biological treatment with the rates of removal related to the nitrification rates and the sludge age. The removal efficiency of the treatment processes were in the order activated sludge $>$ oxidation ditch $>$ biofilter $>$ rotating biological contactors. Activated sludge plant configured for biological nutrient removal showed better removal of the endocrine disrupting chemicals compared to conventional activated sludge plant effluents. Tertiary treatment was also significant in the removal process through solids removal. Overall mechanisms of removal were biodegradation and sorption unto sludge biomass. Phytoremediation was also significant in the removal processes. The endocrine disrupting chemicals persisted in the anaerobic sludge digestion process with percentage removals ranging fro 10-48\%. Sorption of the endocrine disrupting chemicals onto the sludge increased with increasing values for the partitioning coefficients and the organic carbon contents of the sludge.
\end{abstract}

Keywords: Biodegradation; Endocrine disrupting compounds; Removal efficiency; Sludge; Wastewater treatment

\section{INTRODUCTION}

The presence of endocrine disrupting chemicals (EDCs) in the aquatic environment is a major environmental issue which has attracted increased attention internationally in the last decade. These chemicals are mainly discharged to the environment from wastewater treatment effluent (Nakada et al., 2006; Gomez et al., 2007; Goyal et al., 2008; Miege et al., 2009; Gabet-Giraud et al., 2010).

The natural steroid hormones estrone (E1) and $17 \beta$ -estradiol (E2), the closely related synthetic hormone $17 \alpha$-ethinyestradiol (EE2) and xenostrogens like nonylphenol (NP) and its ethoxylates have been shown to occur in wastewater effluent across the globe (Johnson et al., 2000; Litved, 2006; Gomez et al., 2007; Pothitou and Voutsa, 2008; Miege et al., 2009). They are also among the most estrogenic components of domestic sewage effluent (Jobling et al., 1998; Ternes et al., 1999a; Birkett and Lester 2003; Wu and He,

$\triangle$ *Corresponding Author Email: A.Ifelebuegu@coventry.ac.uk Tel.: +4424 7688 835; Fax: +4424 76888400
2010). The natural and synthetic estrogens are excreted primarily as a variety of inactive glucuronide or sulphate conjugates by the human population (Ternes et al., 1999b; D'Ascenzo et al., 2003; Gong et al., 2009; Fouial-Djebbar et al., 2010). Although these estrogen metabolites are deconjugated by bacteria present in sewage and mixed liquor (Shi et al., 2004; Czajka and Londry, 2006), the deconjugated steroids are however, detected in the effluent at concentrations close to the total expected based on excretion values (Johnson et al., 2000). EE2 has the highest endocrine disrupting potency; it is found at low concentrations and is also recalcitrant to biodegradation (Esperanza et al., 2007; Haiyan et al., 2007; Hashimoto et al., 2007). NP is a transformation product of nonylphenol ethoxylates (NPnEOs) which is used in many industrial and commercial process including textile industry processes, and in cosmetic and detergent manufacture (Birket and Lester, 2003; Chien and Shih, 2007). Although the use of NPnEOs has been banned under an EU 
regulation (Regulation no. 1816, 2004), it is still allowed in certain industry with their wastewater treatment facilities (Di Gioia et al, 2009).

Various studies across the globe have shown a broad range of values in the performance of wastewater treatment plants. A study of mass balance of estrogens in sewage treatment works (STW) in Germany demonstrated that most of the estrogenic activity in the wastewater was biodegraded during treatment rather than adsorbed onto suspended solids (Korner et al., 2000). In a study of Japanese STWs by Matsui et al. (2000), it was shown that $10 \%$ removal of E2 occurred across the primary sedimentation, $87 \%$ across the nitrifying activated sludge and a further $22 \%$ removal across the tertiary sand filters. The overall removal of $87 \%$ was reported. Baronti et al. (2000) reported removal rates/efficiency of $95 \%, 87 \%, 61 \%$ and $85 \%$ for estriol, E2, E1 and EE2 respectively. In the study, the efficiency for estrone removal was lowest. It exhibited an increase in concentration from influent to effluent in some of the sites. Nasu et al. (2001) also showed E2 concentrations increasing from raw influent to primary effluent within Japanese STW (before falling during biological treatment), which suggest that perhaps some further deconjugation was still taking place. In another study of the Japanese STW by Hashimoto et al. (2007) a removal efficiency of 11-83\% were reported for $\mathrm{E} 1$ in conventional activated sludge plant, with E2 removal of up to $86 \%$. Kanda and Churchley (2008) also reported a removal of $97.8 \%$ and $96.3 \%$ removal for $\mathrm{E} 1$ and $\mathrm{E} 2$ respectively in a conventional activated sludge plant. Thus the biodegradation of estrogens is well established (Stavrakis et al., 2008). However, currently wastewater treatment plants are not optimised to maximise estrogen removal (Koh et al., 2008) as they were not originally designed to remove EDCs and are just able to remove partly most of the EDCs (Janex-Habibi et al., 2009).

Although a number of researches have been done on the removal of EDCs in wastewater, majority of these investigations were focused on monitoring EDCs concentrations in influent and effluent of wastewater treatment plants. Published results that addressed the behaviour of this EDCs in the unit processes of different wastewater treatment plants (WWTP) using composite sampling are scarce. A critical understanding of the behaviour of EDCs in all the unit processes of treatment plants is required in order to optimise these processes for effective removal of the EDCs. The current study examined the behaviour and fate of E1, E2, EE2 and NP in the unit processes of four different wastewater treatment plants located in the Midlands of the United Kingdom. Both wastewater and sludge treatment processes were investigated

\section{MATERIALS AND METHODS}

Material and reagents

All standards were of analytical grade and were obtained from Sigma-Aldrich (Gillingham, UK). The reagents were purchased from Fischer Scientific (Loughborough, UK) and were all of high purity over $98 \%$. ENV+ solid phase extraction (SPE) cartridges were purchased from IST (Glamorgan, UK) and extraction was on the Waters Sep-Pak Vacuum Manifold with a vacuum pump (Waters, Watford, UK).

\section{Sample collection and treatment}

Four Wastewater Treatment Plants (WWTP) A, B, $\mathrm{C}$ and $\mathrm{D}$ located in the Midlands, UK were investigated. WWTP A and B process wastewater for urban areas and $C$ and $D$ for rural areas. The different treatment types that have been chosen are representative of the common methods of treatment used in the region and the UK generally. The plants characteristics are described in Table 1. Samples were collected from various treatment points representative of the treatment unit processes available at the sites. Wastewater samples were collected (where available) from raw wastewater (RW), crude wastewater and sludge liquor returns (MW), settled wastewater (SW), activated sludge plant effluent (ASP), biofilter effluent (BF), rotating biological contactor effluent (RBC), sand filtered final effluent (SFE) and reed bed effluent (REB). The samples were collected in two sampling campaigns (one week each) in 2008. $24 \mathrm{~h}$ flow proportional composite samples (half hourly sampling frequency) were collected using ISCO 3710 composite samplers (Teledyne Isco, Wierd, Belgium) in glass bottles preconditioned with preservatives, $0.5 \mathrm{~g}$ copper nitrate and $6 \mathrm{~mL}$ hydrochloric acid (Kanda and Churchley, 2008). The samples from the autosamplers were transferred into amber coloured glass bottles daily and stored in ice cold containers and transported to the laboratory for immediate extraction and subsequent analysis. The sludge samples were collected on the last day of each of the sampling campaigns from the primary sludge tanks and digested sludge tanks. The sludge were digested by anaerobic digestion under mesophilic conditions. 
Int. J. Environ. Sci. Tech., 8 (2), 245-254, Spring 2011

Table 1: Characteristics of wastewater treatment plants

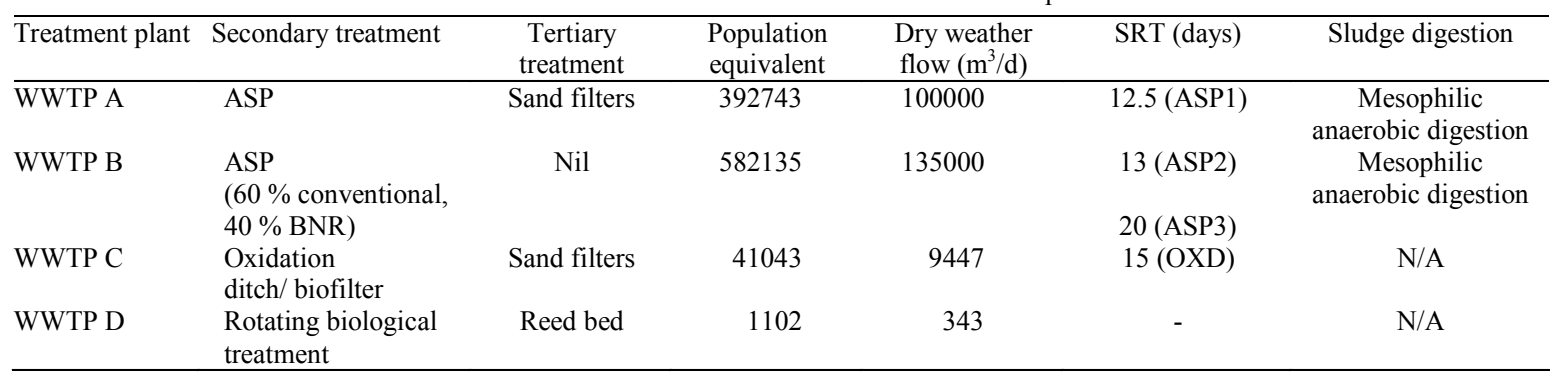

Sample analysis and clean up

Wastewater samples

The EDCs in the wastewater samples were extracted and cleaned up using gel permeation chromatography and solid phase extraction before analysis using LCMS/ MS (Applied Biosystems, Carlsbad, California). Details of the methods applied have been previously described elsewhere (Kanda and Churchley, 2008; SCA, 2005). Sanitary parameters were analysed according to established methods (APHA et al., 1992).

\section{Sludge samples}

Sludge samples were extracted and cleaned using the method developed by Patrolecco et al. (2004). The method was validated for accuracy and precision by analyzing samples spiked with known amounts of EDCs. Recoveries for E1, E2, EE2 and NP were consistent with other extraction methods. For extraction, $50 \mathrm{~mL}$ of Tween 80 aqueous solution was added into approximate mass of $2.5 \mathrm{~g}$ of freeze-dried sludge samples. The resultant suspension was thoroughly mixed at room temperature using a magnetic stirrer (at $300 \mathrm{rpm}$ ). The extract was then allowed to settle for about $10 \mathrm{~min}$, and then transferred to $50 \mathrm{~mL}$ centrifuge tubes and centrifuged at $4,000 \mathrm{rpm}$ for $20 \mathrm{~min}$. The extracts (supernatant) from the centrifuged aqueous solution were passed through SPE using LC-18 cartridges set up on a SPE vacuum manifold after pre-conditioning. The analytes were eluted from the SPE cartridges with $10 \mathrm{~mL}$ acetone. The extracts obtained were then concentrated to an approximate volume of $1 \mathrm{~mL}$ under a gentle stream of nitrogen and then reconstituted with Methanol: $\mathrm{H}_{2} \mathrm{O} 55: 45(\mathrm{v} / \mathrm{v})$ to a final volume of $2 \mathrm{~mL}$ for LC MS/MS analysis.

\section{Sludge partitioning test}

Secondary sludge from the four plants was used in carrying out a partitioning test for the selected EDCs.
$50 \mathrm{~mL}$ of sludge aliquots were added into $250 \mathrm{~mL}$ glass flasks with mix standard solutions of E1, E2, EE2 and NP at concentrations ranging from 100 to $1000 \mu \mathrm{g} / \mathrm{L}$. Equilibration was achieved by stirring the mixtures using a magnetic stirrer for $2 \mathrm{~h}$ and centrifuged at $4000 \mathrm{rpm}$ for $15 \mathrm{~min}$ to separate the aqueous phase from the sludge. The sludge was then filtered and the supernatant solutions were removed and analyzed for the equilibrium concentrations of each EDC. The solid phase EDCs concentrations were determined on mass balance basis.

The sludge/aqueous partition coefficient $\left(\mathrm{K}_{\mathrm{d}} \mathrm{L} /\right.$ $\mathrm{kg}$ ) for each compound were calculated using the relationship:

$$
K_{d}=\frac{C_{s}}{C_{a q}}
$$

Where $\mathrm{C}_{\mathrm{s}}$ is the concentration of EDC adsorbed by sludge in $\mathrm{mg} / \mathrm{kg}$ and while $\mathrm{C}_{\mathrm{aq}}$ is the concentration of the compound in aqueous phase in $\mathrm{mg} / \mathrm{L}$.

The $\mathrm{K}_{\mathrm{OC}}$ values were calculated by using the expression in equation 2 .

$$
K O C=\frac{K d x 100}{\% T O C}
$$

\section{RESULTS AND DISCUSSION}

\section{Occurrence of selected EDCs in WWTPs}

The selected EDCs were detected in all the plants investigated except EE2 which was not detected in the influent and effluent of WWTP D. The mean concentrations of the EDCs in every step of the unit processes for both sampling campaigns are presented in Table 2. The mean influent concentrations for E1 
in all the four plants ranged from $64.51-116.06 \mathrm{ng} / \mathrm{L}$. E2 ranged from 15.67 to $82.55 \mathrm{ng} / \mathrm{L}$ and $\mathrm{EE} 2$ was quantified between 0.5 and $1.54 \mathrm{ng} / \mathrm{L}$ for sites $\mathrm{A}, \mathrm{B}$ and $\mathrm{C}$ with no detection at site $\mathrm{D}$. The results are consistent with those reported in various literatures. (Nakada et al., 2006; Zhang and Zhou, 2008; Miege et al., 2009; Gabet-Giraud et al., 2010; Zhou et al., 2010). It can also be seen in
Table 2 that the influent EDCs concentrations in urban wastewater (WWTPA and B) are higher than the rural wastewater (WWTP C and D). The average daily variations for the first sampling campaigns for site B is presented in Fig. 1. Similar variations were obtained for sites $A$ and $C$ (not included). The daily variations of the EDCs are relatively low at $\geq 5 \%$ standard deviation.

Table 2: Distribution of EDCs (ng/L) in the unit processes of the wastewater treatment plants for two sampling campaigns, standard deviations are presented in parentheses

\begin{tabular}{|c|c|c|c|c|c|c|c|c|c|}
\hline \multirow[b]{2}{*}{ WWTP } & \multirow{2}{*}{$\begin{array}{l}\text { Sampling } \\
\text { Point }\end{array}$} & \multicolumn{2}{|c|}{ E1 (average $( \pm \mathrm{SD})$} & \multicolumn{2}{|c|}{ E2 (average $( \pm \mathrm{SD})$} & \multicolumn{2}{|c|}{ EE2 (average $( \pm \mathrm{SD})$} & \multicolumn{2}{|c|}{ NP (average $( \pm \mathrm{SD})$} \\
\hline & & $1^{\text {st }}$ & $2^{\text {nd }}$ & $1^{\text {st }}$ & $2^{\text {nd }}$ & $1^{\text {st }}$ & $2^{\text {nd }}$ & $1^{\text {st }}$ & $2^{\text {nd }}$ \\
\hline \multirow[t]{5}{*}{ A } & RW & $85.7\left( \pm 11.2^{*}\right)$ & $119.3( \pm 30.0)$ & $51.3( \pm 16.8)$ & $44.2( \pm 10.2)$ & $1.3( \pm 0.6)$ & $0.9( \pm 0.6)$ & $31.3( \pm 10.3)$ & $41.0( \pm 5.8)$ \\
\hline & MW & $98.1( \pm 21.3)$ & $130.5( \pm 22.3)$ & $36.1( \pm 10.4)$ & $41.7( \pm 7.9)$ & $1.1( \pm 0.2)$ & $0.8( \pm 0.4)$ & $31.0( \pm 13.2)$ & $41.7( \pm 9.1)$ \\
\hline & SW & $87.3( \pm 8.1)$ & $121.3( \pm 14.1)$ & $30.1( \pm 6.6)$ & $42.8( \pm 11.4)$ & $1.0( \pm 0.2)$ & $0.9( \pm 0.5)$ & $27.5( \pm 7.8)$ & $38.3( \pm 6.5)$ \\
\hline & ASP1 & $41.4( \pm 6.9)$ & $54.3( \pm 10.4)$ & $5.3( \pm 2.3)$ & $1.1( \pm 1.0)$ & $0.6( \pm 0.4)$ & $0.5( \pm 0.2)$ & $2.3( \pm 0.8)$ & $7.9( \pm 1.2)$ \\
\hline & SFE & $10.0( \pm 2.4)$ & $20.3( \pm 4.5)$ & $2.3( \pm 0.6)$ & $<1$ & $0.5( \pm 0.2)$ & $0.4( \pm 0.1)$ & $1.8( \pm 0.3)$ & ND \\
\hline \multirow[t]{6}{*}{ B } & RW & $116.1( \pm 20.2)$ & $109.1( \pm 22.1)$ & $74.4( \pm 17.2)$ & $82.6( \pm 23.4)$ & $1.1( \pm 0.5)$ & $1.5( \pm 1.1)$ & $51.1( \pm 15.1)$ & $33.8( \pm 10.2)$ \\
\hline & MW & $132.4( \pm 24.2)$ & $140.3( \pm 28.2)$ & $67.7( \pm 21.2)$ & $79.6( \pm 18.1)$ & $1.0( \pm 0.4)$ & $1.8( \pm 0.7)$ & $48.0( \pm 10.2)$ & $30.0( \pm 6.1)$ \\
\hline & SW & $116.7( \pm 14.6)$ & $112.3( \pm 19.7)$ & $60.8( \pm 14.1)$ & $72.6( \pm 19.4)$ & $0.9( \pm 0.3)$ & $1.3( \pm 0.4)$ & $44.4( \pm 7.9)$ & $30.2( \pm 3.4)$ \\
\hline & ASP 2 & $20.1( \pm 3.7)$ & $39.4( \pm 8.4)$ & $5.9( \pm 1.8)$ & $5.0( \pm 1.1)$ & $0.6( \pm 0.2)$ & $0.8( \pm 0.3)$ & $5.8( \pm 1.1)$ & $2.3( \pm 7.8)$ \\
\hline & ASP 3 & $11.5( \pm 2.3)$ & $20.1( \pm 4.9)$ & $1.1( \pm 0.5)$ & $1.0( \pm 0.5)$ & $0.4( \pm 0.3)$ & $0.2( \pm 0.1)$ & $1.4( \pm 0.4)$ & ND \\
\hline & $\mathrm{FE}$ & $14.5( \pm 2.5)$ & $22.4( \pm 1.8)$ & $1.3( \pm 0.6)$ & $1.3( \pm 0.7)$ & $0.4(0.5)$ & $0.4( \pm 0.2)$ & ND & ND \\
\hline \multirow[t]{6}{*}{$\mathrm{C}$} & RW & $72.9( \pm 14.2)$ & $92.2( \pm 15.5)$ & $35.7( \pm 10.9)$ & $27.5( \pm 11.5)$ & $0.7( \pm 0.4)$ & $0.5( \pm 0.3)$ & $15.3( \pm 7.7)$ & $20.8( \pm 6.9)$ \\
\hline & MW & $88.1( \pm 16.2)$ & $98.9( \pm 11.2)$ & $28.7( \pm 8.7)$ & $23.1( \pm 7.5)$ & $0.7( \pm 0.3)$ & $0.5( \pm 0.2)$ & $14.9( \pm 5.5)$ & $16.5( \pm 4.8)$ \\
\hline & SW & $70.1( \pm 6.7)$ & $90.9( \pm 9.8)$ & $23.1( \pm 7.7)$ & $20.7( \pm 5.9)$ & $0.6( \pm 0.3)$ & $0.4( \pm 0.2)$ & $12.3( \pm 5.8)$ & $15.2( \pm 2.8)$ \\
\hline & OXD & $21.7( \pm 5.1)$ & $44.2( \pm 11.6)$ & $1.2( \pm 0.8)$ & $1.9( \pm 1.1)$ & $0.3( \pm 0.1)$ & $0.3( \pm 0.1$ & $3.1( \pm 1.1)$ & ND \\
\hline & $\mathrm{BF}$ & $29.0( \pm 6.3)$ & $51.5( \pm 8.7)$ & $8.2( \pm 2.1)$ & $7.9( \pm 1.8)$ & $0.5( \pm 0.2)$ & $0.4( \pm 0.2)$ & $6.3( \pm 1.2)$ & $3.0( \pm 1.2)$ \\
\hline & SFE & $8.6( \pm 1.2)$ & $19.5( \pm 5.3)$ & $0.9( \pm 0.6)$ & $1.0( \pm 0.2)$ & $0.3( \pm 0.2)$ & $0.4( \pm 0.1)$ & $2.9( \pm 0.7)$ & ND \\
\hline \multirow[t]{3}{*}{ D } & RW & $64.5( \pm 18.7)$ & $83.8( \pm 17.3)$ & $28.5( \pm 8.1)$ & $15.7( \pm 4.7)$ & ND & ND & $3.1( \pm 0.8)$ & $6.0( \pm 2.9)$ \\
\hline & $\mathrm{RBC}$ & $50.1( \pm 15.6)$ & $69.1( \pm 18.9)$ & $20.9( \pm 4.3)$ & $12.3( \pm 5.6)$ & ND & ND & $1.8( \pm 0.4)$ & $1.0( \pm 0.4)$ \\
\hline & RBED & $12.3( \pm 3.6)$ & $14.7(2.5)$ & $2.5( \pm 0.7)$ & $3.9( \pm 1.1)$ & ND & ND & ND & ND \\
\hline
\end{tabular}

$(\mathrm{N}=7) ; \quad \mathrm{ND}=$ Not Detected; $*_{ \pm}=\mathrm{SD}$

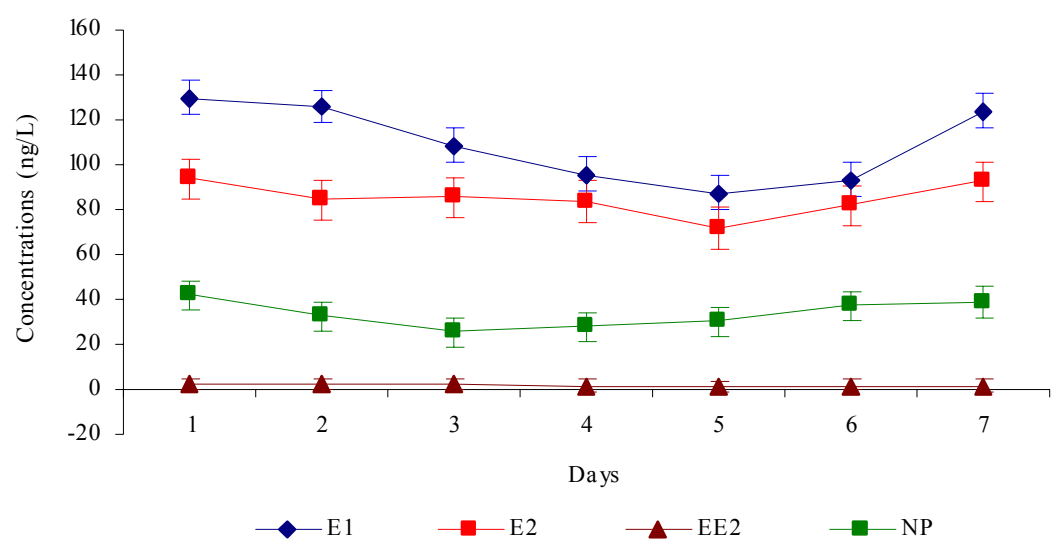

Fig. 1: Average daily variation of EDCs for first sampling campaign for WWTP B 


\section{Removal rates of treatment processes}

The global removal efficiency as a measure of the influent concentrations of the EDCs (primary, biological and tertiary treatment where available) are shown in Fig. 2. The ranges of removals were 81-86 \%, 83-97 \%, 41-58 \% and 91-100\% for E1, E2, EE2 and NP respectively. EE2 persisted more in the effluent despite being present in the influent of the WWTP at very low concentrations compared to the others. This shows that the synthetic hormone EE2 is more recalcitrant to removal in wastewater treatment compare to the natural hormones. WWTP B showed better removal efficiency for all the EDCs despite not having any tertiary treatment process like the other three plants. The reasons for these differences are discussed in the succeeding sections.

\section{Removal rate of unit processes \\ Primary treatment}

Table 2 show that for Sites A-C there were initial increases in the concentrations of $\mathrm{E} 1$ at sampling point MW (made up of the crude sewage and sludge liquor from the dewatering process) and also the settled sewage for sites $A$ and $B$. This apparent anomaly in the increase in E1concentration is explained by the biological conversion of E2 to E1 during the treatment process and in the sludge route. This abnormal behaviour has also been observed in previous studies (Nasu et al., 2001; Jurgens et al., 2002; Hashimoto et al., 2007; Ren et al., 2007). This also explains why E1 persist in both the effluent and sludge from the WWTPs. This increase in E1 concentration in the crude sewage after the mixing with sludge return liquor suggests that the return liquor has a higher concentration of E1. This supports the assertion that both E1 and the more rapidly degradable E2 are adsorbed onto the sludge biomass and that the removal mechanism is both a combination of sorption and biodegradation as suggested by Johnson and Sumpter (2001). Xu et al. (2008) have also shown that EE2 is adsorbed unto sludge biomass by predominantly physiosorption and are therefore easily able to move from the solid phase to the liquid phase by desorption. E2, EE2 and NP were progressively removed during the primary treatment stages unlike E1. The removal during the primary treatment process can be attributed to sorption onto sludge.

\section{Biological treatment}

The mean removal rates for all the biological treatment processes are presented in Fig. 3. The biological treatment processes are the activated sludge plants at WWTP A (ASP1), WWTP B (ASP2 and ASP3), oxidation ditch and biofilter both at WWTP C, and the RBC at WWTP D. The removal rates compared to the global removal rates earlier shown in Fig. 2 demonstrate that majority of the EDCs are removed during the biological treatment stage except at WWTP $\mathrm{D}$ where the reed bed process performed better than the RBC process. It can be seen that ASP3 showed the highest removal rate with $\mathrm{RBC}$ showing the least removal rate. ASP2 and ASP3 are co-located at WWTP $\mathrm{B}$, and the later is configured for biological nutrient removal. As shown in Table 1 the sludge age for ASP3 is highest (20 days) compared to ASP1 (12.5 days) and ASP2 (13 days). This could explain the reason for the

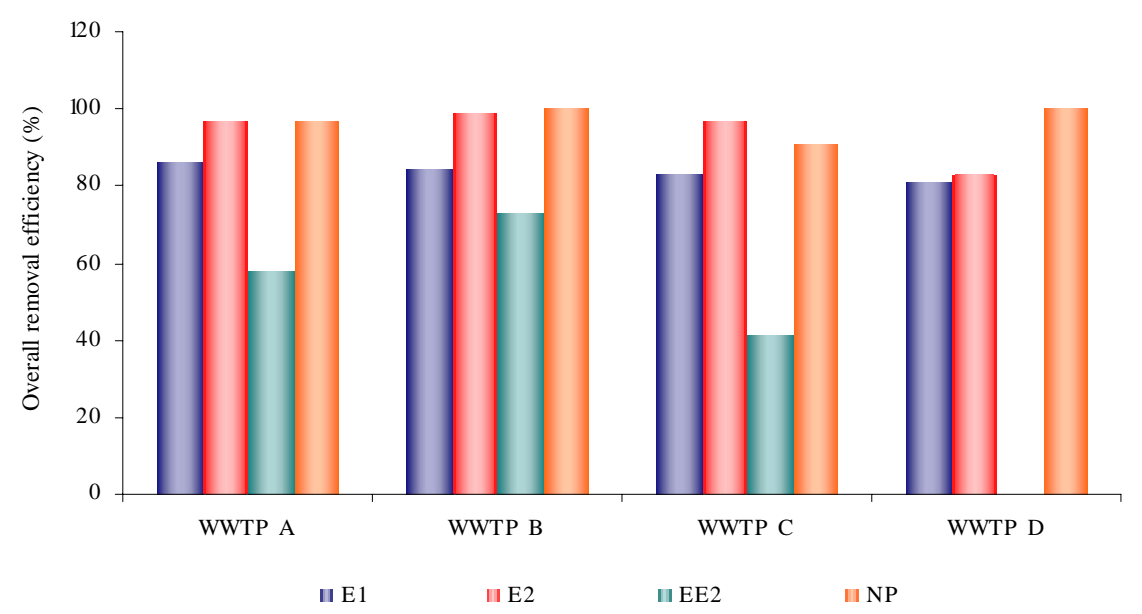

Fig. 2: Overall removal rates of EDCs in all WWTP 
A. O. Ifelebuegu

relatively better performance in the removal of all the EDCs. Sludge age is an important factor for the removal of EDCs as longer sludge age allows the growth of microorganism with the capacity to degrade the compounds (Janex-Habibi et al., 2009; Stasinakis et al., 2009). The Oxidation ditch process showed slightly lower removal rate compared to the ASPs and better rate in comparison with the biological filter process and rotating biological contactors (Fig. 3). This can be attributed to the differences in their nitrification rates. Better removal was obtained for all the EDCs with increasing rate of nitrification for each of the WWTP. This agrees with the findings of Vader et al. (2000) where they found that no degradation of EE2 was observed when there was insignificant nitrifying capacity. Biofilters and RBC have low nitrification rates relative to ASPs and oxidation ditches. This will explain while ASP and the oxidation ditch processes gave better performance. Also for the ASPs and oxidation ditch higher biosolids are produced which is wasted as surplus activated sludge. More of the EDCs will adsorb on to the excess sludge produced as the $\mathrm{K}_{\mathrm{d}}$ and $\mathrm{K}_{\mathrm{OC}}$

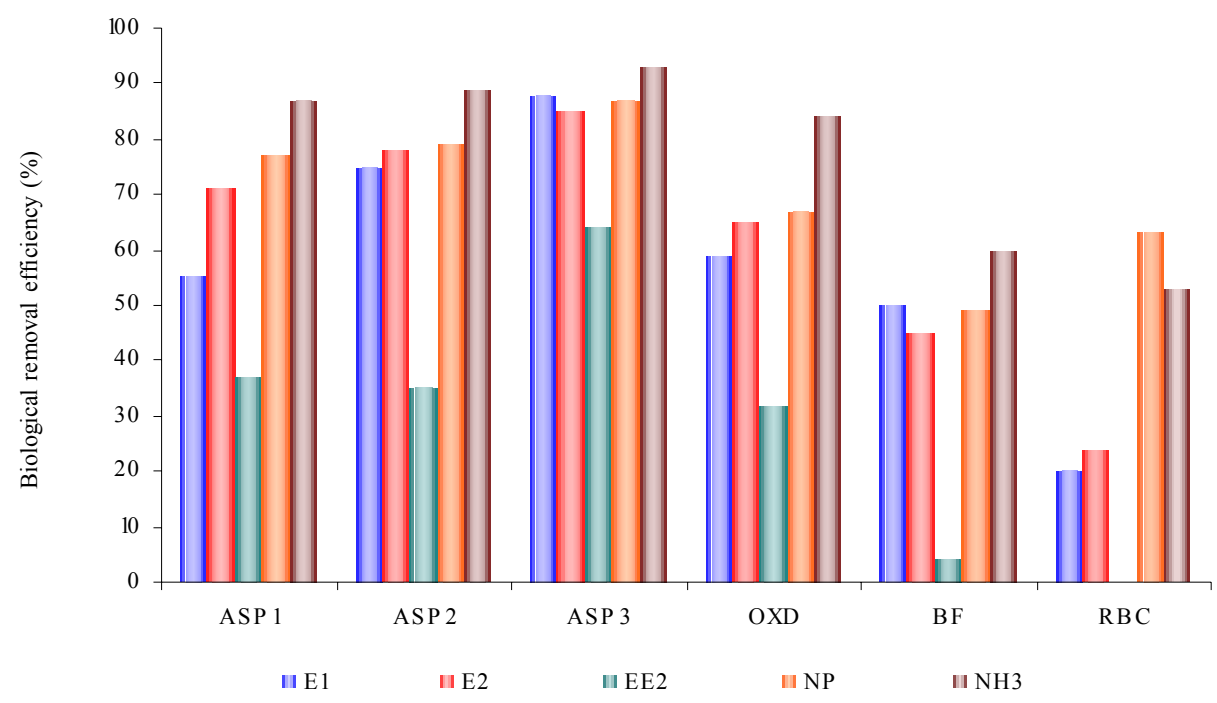

Fig. 3: Biological removal rates of specific biological treatment processes

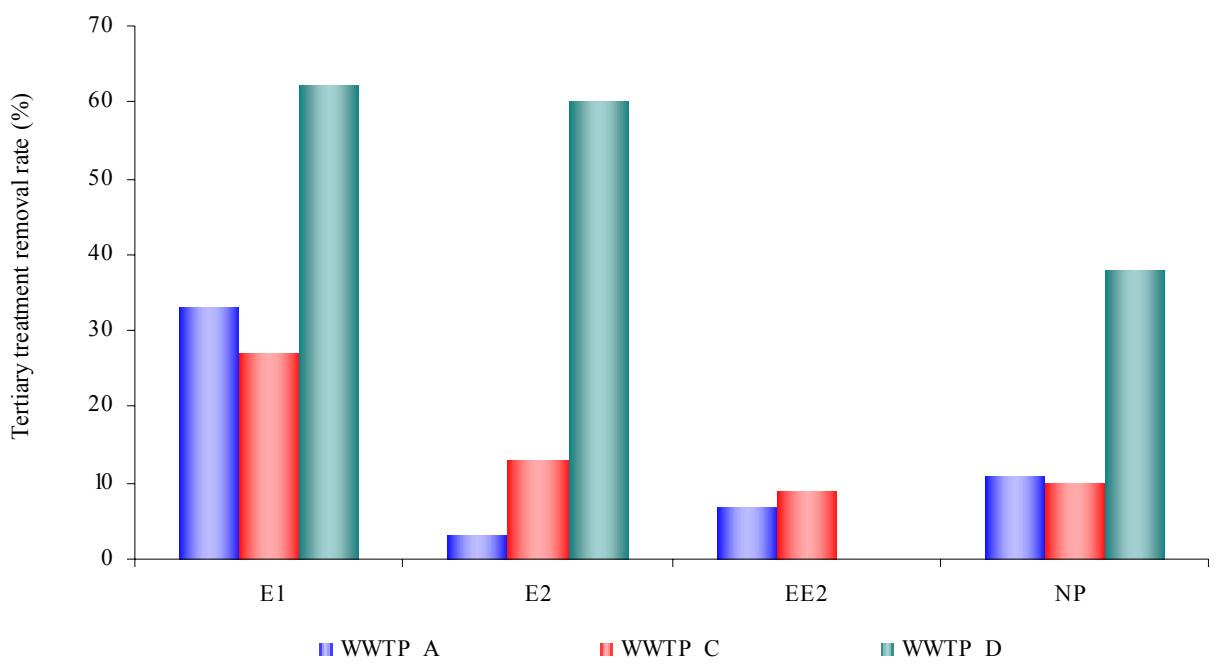

Fig. 4: Tertiary removal rates of specific biological treatment processes 
values in Table 4 show significant partitioning of the EDCs to sludge biomass with Log $K_{d}$ values ranging from 2.41 to 2.83, $\log \mathrm{K}_{\mathrm{oc}}$ ranging from 2.85 to 3.3.32.for all the compounds, similar to earlier report by Ifelebuegu et al., 2010.

\section{Tertiary treatment}

WWTP A, C and D had tertiary treatment stages. Sand filters for sites A and C and reed bed for site D. The removal rates for The EDCs during tertiary treatments are presented in Fig. 4. It can be seen that at WWTP D the reed bed process showed better removal of $62 \%, 60 \%$ and $38 \%$ compared to the secondary biological process which showed a removal of $20 \%, 24 \%$ and $63 \%$ of the influent E1, E2 and NP concentrations respectively. The removal processes for the reed bed are likely to be a combination of sorption to solids and biodegradation in the roots of the reeds as plant roots provides additional surface for sorption and diverse microorganisms for the phytoremediation process. Solids removal during the reed bed process contribute to the removal process as the adsorption coefficients reported in Table 4 show that the EDCs adsorb significantly to the solid phase. Biodegradation is also possible as previous research by Imai et al. (2007) demonstrated that phenolic EDCs are significantly removed by plants through enzyme metabolism. WWTP A and C also showed some removal during the sand filtration process. This also demonstrates that sorption to solids is a removal mechanism for the EDCs as supported by Xu et al. (2008).
EDCs in sludge and sludge treatment process

The secondary sludge, mixed sludge from all four sites and digested sludge from WWTP A and B were analysed for the selected EDCs. Table 3 shows the Concentrations of the EDCs in untreated sludge and the digested sludge. It can be seen that E1 showed highest concentration of $88-118 \mu \mathrm{g} / \mathrm{kg}$ in sludge compared to E2 (4-16 $\mu \mathrm{g} / \mathrm{kg})$, EE2 $(0-1.6 \mu \mathrm{g} / \mathrm{kg})$ and NP (32-123 $\mu \mathrm{g} / \mathrm{kg})$. This agrees with the earlier observation that levels of E1 were higher in the sludge liquors of WWTP A, B and C resulting from increases during the primary treatment processes. Similar levels of other pharmaceutical were reported in sewage sludge by Lillenberg et. al.,2010. The higher levels of the compounds present in the untreated sludge also demonstrates that sorption unto activated sludge biomass is a significant removal mechanism of EDCs during wastewater treatment. It can also be seen that the removal rate of the EDCs during anaerobic digestion is low. This finding is consistent with the study carried out by Czajka and Londry (2006). The EDCs persisted in the anaerobic sludge digestion process with percentage removal of $21-24 \%$ for E1, 18-32 \% for E2, $10-15 \%$ for EE2 and $44-48 \%$ for NP. This shows that under anoxic/anaerobic conditions in the receiving environment, these EDCs have the potential to bioconcentrate (Lai et al., 2002a, 2002b) or accumulate (Gomes et al., 2004; Czajka and Londry, 2006) when sludge is applied to the environment. It was also observed that the concentrations of the

Table 3: Distribution of EDCs ( $\mu \mathrm{g} / \mathrm{kg})$ ) in mixed raw sludge (MSL) and digested sludge (DSL)

\begin{tabular}{|c|c|c|c|c|c|c|c|c|}
\hline \multirow[t]{2}{*}{ WWTP } & \multicolumn{2}{|c|}{ E1 $( \pm \mathrm{SD})(\mu \mathrm{g} / \mathrm{kg})$} & \multicolumn{2}{|c|}{ E2 $( \pm \mathrm{SD})(\mu \mathrm{g} / \mathrm{kg})$} & \multicolumn{2}{|c|}{ EE2 $( \pm \mathrm{SD})(\mu \mathrm{g} / \mathrm{kg})$} & \multicolumn{2}{|c|}{$\mathrm{NP}( \pm \mathrm{SD})(\mu \mathrm{g} / \mathrm{kg})$} \\
\hline & MSL & DSL & MSL & DSL & MSL & DSL & MSL & DSL \\
\hline A & $106.65( \pm 8.5)$ & $80.54( \pm 8.7)$ & $8.65( \pm 1.8)$ & $7.08( \pm 1.1)$ & $1.89( \pm 0.4)$ & $1.61( \pm 0.3)$ & $122.6( \pm 7.6)$ & $68.97( \pm 6.7)$ \\
\hline B & $87.94( \pm 5.3)$ & $67.11( \pm 5.8)$ & $3.76( \pm 0.7)$ & $2.55( \pm 0.2)$ & $1.64( \pm 0.2)$ & $1.48( \pm 0.1)$ & $87.39( \pm 5.8)$ & $46.57( \pm 3.8)$ \\
\hline D & $117.86( \pm 11.2)$ & N/A & $15.65( \pm 2.4)$ & N/A & nd & N/A & $32.03( \pm 3.3)$ & N/A \\
\hline
\end{tabular}

nd $=$ not detected

Table 4: Partitioning coefficients of EDCs in the secondary sludge

\begin{tabular}{|c|c|c|c|c|c|c|}
\hline \multirow[t]{2}{*}{$\overline{\text { Sites }}$} & \multirow[t]{2}{*}{ Plants } & \multirow[t]{2}{*}{ TOC \% } & \multicolumn{4}{|c|}{ Log $\left.K_{d} @ 25^{0} \mathrm{C}, \mathrm{L} / \mathrm{kg}\right)\left(\log \mathrm{K}_{\mathrm{OC}}\right)$} \\
\hline & & & E1 & E2 & EE2 & NP \\
\hline A & ASP1 & 30 & $2.41(2.93)$ & 2.67 (3.19) & $2.76(3.28)$ & $2.32(2.85)$ \\
\hline \multirow[t]{2}{*}{ B } & ASP2 & 28 & $2.47(3.02)$ & $2.65(3.20)$ & $2.76(3.32)$ & $2.31(2.86)$ \\
\hline & ASP3 & 24 & 2.37 (2.99) & $2.59(3.21)$ & $2.69(3.31)$ & $2.29(2.91)$ \\
\hline \multirow[t]{2}{*}{$\mathrm{C}$} & OXD & 31 & $2.52(3.03)$ & $2.65(3.16)$ & $2.77(3.28)$ & $2.34(2.85)$ \\
\hline & $\mathrm{BF}$ & 30 & $2.49(3.02)$ & $2.68(3.21)$ & $2.78(3.30)$ & $2.37(2.89)$ \\
\hline $\mathrm{D}$ & RBC & 35 & $2.60(3.06)$ & $2.71(3.17)$ & $2.83(3.29)$ & $2.39(2.85)$ \\
\hline
\end{tabular}


EDCs in the untreated sludge for the different WWTP increased with the increased values of $\log \mathrm{K}_{\mathrm{d}}$ and organic carbon contents.

\section{Removal mechanism}

The findings presented in this paper have demonstrated that the principal mechanism of removal of EDCs during the wastewater treatment process is biodegradation by microorganisms and also sorption unto biosolids contrary to the report of Korner et. al. (2000). Removal by phytoremediation (WWTP D) was also shown to be significant. However, the scope of this study did not cover plant removal mechanism of EDCs.

\section{CONCLUSION}

Overall removal efficiencies of all the EDCs ranged from $41 \%$ to $100 \%$. The removal rates were in the order ASP $>$ OXD $>$ BF $>$ RBC. The ASP configured for biological nutrient removal showed better performance compared to the conventional ASPs. The removals were predominately during the secondary biological treatment. The removal rates for the treatment processes corresponded with the rate of nitrification. For ASPs higher sludge ages resulted in better removal rate for all the EDCs. Tertiary treatment was also significant in the removal process through solids removal. Overall mechanisms of removal were biodegradation and sorption unto sludge biomass. The EDCs persisted in the anaerobic sludge digestion process with percentage removal ranging from $10-48 \%$, suggesting that the compounds may persist in the environment under anoxic/anaerobic conditions. Sorption of the EDCs onto the sludge increased with increasing values for the partitioning coefficient and the organic carbon contents of the sludge.

\section{ACKNOWLEDGEMENTS}

The author wishes to thank Severn Trent Water for the permission to carry out sampling at their sites and also for the material support by the Research and Development Group during the research.

\section{REFERENCES}

APHA; AWWA; WEF, (1992). Standard methods for the examination of water and wastewater. $18^{\text {th }}$ Ed. American Public Health Association, American Water Works Association and the Water Environment Federation. Washington DC., USA.
Baronti, C.; Curini, R.; D’Ascenzo, G.; Di Corcia, A.; Samperi, R., (2000). Monitoring natural and synthetic estrogens at activated sludge treatment plants and in receiving river water. Environ. Sci. Tech., 34 (24), 5059-5066 (8 pages).

Birkett, J. W.; Lester, J. N., (2003). Endocrine Disrupters in Wastewater and Sludge Treatment Processes. CRC Press LLC, Florida.

Chien, M. K.; Shih, L. H., (2007). An empirical study of the implementation of green supply chain management practices in the electrical and electronic industry and their relation to organizational performances. Int. J. Environ. Sci. Tech., 4 (3), 383-394 (12 pages).

Czajka, C. P.; Londry, K. L., (2006). Anaerobic biotransformation of estrogens. Sci. Total Environ., 367 (2-3), 932-941 (10 pages).

D'Ascenzo, G.; Di Corcia, A.; Gentili, A.; Mancini, R.; Mastropasqua, R.; Nazzari, M.; Samperi, R., (2003). Fate of natural estrogen conjugates in municipal sewage transport and treatment facilities. Sci. Total Environ., 302 (1-3), 199-209 (11 pages).

Di Gioia, D.; Sciubba, L.; Bertin, L.; Barberio, C.; Salvadori, L.; Frassinetti S.; Fava, F., (2009). Nonylphenol polyethoxylate degradation in aqueous waste by the use of batch and continuous biofilm bioreactors. Water Res., 43 (12), 2977-2988 (12 pages).

Esperanza, M.; Suidan, M. T.; Marfil-Vega, R.; Gonzalez, C.; Sorial, G. A.; McCauley P.; Brenner, R., (2007). Fate of sex hormones in two pilot-scale municipal wastewater treatment plants: Conventional treatment. Chemosphere, 66 (8), 1535-1544 (10 pages).

Fouial-Djebbar, D.; Badjah Hadji Ahmed, A. Y.; Budzinski, H., (2010). Determination of organochlorine compounds in coastal marine sediments from the southern west of the Mediterranean Sea. Int. J. Environ. Sci. Tech., 7 (2), 271 280 (10 pages).

Gabet-Giraud, V.; Miege, C.; Choubert, J. M.; Martin Ruel, S.; Coquery, M., (2010). Occurrence and removal of estrogens and beta blockers by various processes in wastewater treatment plants. Sci. Total Environ., 408 (19),4257-4269 (13 pages).

Gomes, R. L.; Deacon, H. E.; Lai, K. M.; Birkett, J. W.; Scrimshaw, M. D.; Lester, J. N., (2004). An assessment of the bioaccumulation of estrone in Daphnia magna. Environ. Toxicol. Chem., 23 (1), 105-108 (4 pages).

Gomez, M. J.; Martinez Bueno, M. J.; Lacorte, S.; FernandezAlba, A. R.; Aguera, A., (2007). Pilot survey monitoring pharmaceuticals and related compounds in a sewage treatment plant located on the Mediterranean coast. Chemosphere, 66 (6), 993-1002 (10 pages).

Gong, R.; Liang, J.; Chen, J.; Huang, F., (2009). Removal of bisphenol A from aqueous solution by hydrophobic sorption of hemimicelles. Int. J. Environ. Sci. Tech., 6 (4), 539544 ( 6 pages).

Goyal, P.; Sharma, P.; Srivastava, S.; Srivastava, M. M., (2008). Saraca indica leaf powder for decontamination of $\mathrm{Pb}$ : Removal, recovery, adsorbent characterization and equilibrium modeling. Int. J. Environ. Sci. Tech., 5 (1), 27-34 (8 pages).

Haiyan, R.; Shulan, J.; ud din Ahmad, N.; Dao, W.; Chengwu, C., (2007). Degradation characteristics and metabolic 
pathway of 17 alpha-ethynylestradiol by Sphingobacterium sp. JCR5. Chemosphere, 66 (2), 340-346 (7 pages).

Hashimoto, T.; Onda, K.; Nakamura, Y.; Tada, K.; Miya, A.; Murakami, T., (2007). Comparison of natural estrogen removal efficiency in the conventional activated sludge process and the oxidation ditch process. Water Res., 41 (10), 2117-2126 (10 pages).

Ifelebuegu, A. O.; Theophilus, S. C.; Bateman, M. J., (2010). Mechanistic evaluation of the sorption properties of endocrine disrupting chemicals in sewage sludge biomass. Int. J. Environ. Sci. Tech., 7 (4), 617-622 (6 pages).

Imai, S.; Shiraishi, A.; Gamo, K.; Watanabe, I.; Okuhata, H.; Miyasaka, H.; Ikeda, K.; Bamba, T.; Kazumasa, H., (2007). Removal of phenolic endocrine disruptors by Portulaca oleracea. J. Biosci. Bioeng., 103 (5), 420-426 (7 pages).

Janex-Habibi, M. L.; Huyard, A.; Esperanza, M.; Bruchet, A., (2009). Reduction of endocrine disruptor emissions in the environment: The benefit of wastewater treatment. Water Res., 43 (6), 1565-1576 (12 pages).

Jobling, S.; Nolan, M.; Tyler, C. R.; Brighty, G. C.; Sumpter, J. P., (1998). Widespread sexual disruption in wild fish. Environ. Sci. Tech., 32 (17), 2498-2506 (9 pages).

Johnson, A. C.; Belfroid, A.; Di Corsa, A., (2000). Estimating steroid oestrogen inputs to activated sludge treatment works and observations on their removal from the effluent. Sci. Total Environ., 256 (2-3), 163-173 (11 pages).

Johnson. A. C.; Sumpter J. P., (2001). Removal of endocrine disrupting chemicals in activated sludge treatment process. Environ. Sci. Tech., 35 (24), 4697-4703 (7 pages).

Jurgens, M. D.; Holthaus, K. I. E.; Johnson, A. C.; Smith J. J. L.; Hetheridge, M.; Williams, R., (2002). The potential for estradiol and ethinylestradiol degradation in English Rivers. Environ. Toxicol. Chem., 21 (3), 480-488 (9 pages).

Kanda, R.; Churchley, J., (2008). Removal of endocrine disrupting chemicals during conventional wastewater treatment. Environ. Tech., 29 (3), 315-323 (9 pages).

Koh, Y. K. K.; Chiu, T. Y.; Boobis A.; Cartmell, E.; Scrimshaw, M. D.; Lester, J. N., (2008). Treatment and removal Strategies of natural Estrogens in the Wastewater. Environ. Tech., 29 (1), 245-268 (24 pages).

Korner, W.; Bolz, U.; Sussmuth, W.; Hiller, G.; Schuller, W.; Hanf, V.; Hagenmaier, H., (2000). Input/output balance of estrogenic active compounds in a major municipal sewage plant in Germany. Chemosphere, 40 (9-11), 1131-1142 (12 pages).

Lai, K. M.; Scrimshaw, M. D.; Lester, J. N., (2002a). Biotransformation and bioconcentration of steroid estrogens by Chlorella vulgaris. Appl. Environ. Microbiol., 68 (2), 859-864 (6 pages).

Lai, K. M.; Scrimshaw, M. D.; Lester, J. N., (2002b). Prediction of the bioaccumulation factors and body burden of natural and synthetic estrogens in aquatic organisms in river systems. Sci. Total Environ., 289 (1-3), 159-168 (10 pages).

Lillenberg, M.; Yurchenko, S.; Kipper, K.; Herodes, K.; Pihl, V.; Lõhmus, R.; Ivask, M.; Kuu, A.; Kutti, S.; Litvin, S. V.; Nei, L., (2010). Presence of fluoroquinolones and sulfonamides in urban sewage sludge and their degradation as a result of composting. Int. J. Environ. Sci. Tech., 7 (2), 307-312 (6 pages).
Matsui, S.; Takigami, H.; Matsuda, T.; Taniguchi, N.; Adachi, J.; Kawami, H.; Schimizu, Y., (2000). Estrogens and oestrogen mimics contamination in water and the role of sewage treatment. Water Sci. Tech., 42 (12), 173-179 (7 pages).

Miege, C.; Choubert, J. M.; Ribeiro, L.; Eusebe, M.; Coquery, M., (2009). Fate of pharmaceuticals and personal care products in wastewater treatment plants - conception of a database and first results. Environ. Poll., 157 (5), 17211726 (6 pages).

Nakada, N.; Tanishima, T.; Shinokara, H.; Kiri, K.; Takada, H., (2006). Pharmaceutical chemicals and endocrine disrupters in municipal wastewater in Tokyo and their removal during activated sludge treatment. Water Res., 40 (17), 3297-3303 (7 pages).

Nasu, M.; Oshima, Y.; Tanaka, H., (2001). Study on endocrine disrupting chemicals in wastewater treatment plants. Water Sci. Tech., 43 (2), 101-108 (8 pages).

Patrolecco, L.; Capri, S.; De Angelis, S.; Polesello, S.; Valsecchi, S., (2004). Determination of endocrine disrupting chemicals in environmental solid matrices by extraction with a nonionic surfactant (Tween 80). J. Chromatogr. A., 1022 (12), 1-7 (7 pages).

Pothitou, P.; Voutsa, D., (2008). Endocrine disrupting compounds in municipal and industrial wastewater treatment plants in Northern Greece. Chemosphere, 73 (11), 1716-1723 (8 pages).

Shi, J. H.; Suzuki, Y.; Nakai, S.; Hosomi, M., (2004). Microbial degradation of estrogens using activated sludge and night soil-composting microorganisms. Water Sci. Tech., 50 (8), 153-159 (7 pages).

SCA, (2005). The determination of steroid estrogens in environmental and wastewater using chromatography and mass spectrometery. Standing Committee of Analyst, Environment Agency, Bristol, UK.

Stasinakis, A. S.; Kordoutis, C. I.; Tsiouma, V. C.; Gaatidou, G.; Thomaidis, N. S., (2010). Removal of selected endocrine disrupters in activated sludge systems: Effect of sludge retention time on their sorption and biodegradation. Biores. Tech., 101 (7), 2090-2095 (6 pages).

Stavrakis, C., Hequet, V., Faur, C., Andres, Y., Le-Cloirec, P., Colin, R., (2008). Biodegradation of endocrine disruptors: Case of $17 \beta$-Estradiol and Bisphenol A. Environ. Tech., 29(1), $269-278$ (10 pages).

Ternes, T. A.; Kreckel, P.; Muller, J., (1999a). Behavior and occurrence of estrogens in municipal sewage treatment plants 11. Aerobic batch experiments with activated sludge. Sci. Total Environ., 225 (1-2), 91-99 (9 pages).

Ternes, T. A.; Stumpf, M.; Mueller, J.; Haberer, K.; Wilken, R. D.; Servos, M., (1999b). Behaviour and occurrence of estrogens in municipal sewage treatment plants -1 investigation in German, Canada and Brazil. Sci. Total Environ., 225 (1-2), 81-90 (10 pages).

Vader, J. S.; van Ginkel, C. G.; Sperling, F. M. G. M.; de Jong, J.; de Boer, W.; de Graaf, J. S. van der Most, M.; Stokman, P. G. W., (2000). Degradation of ethinyl estradiol by nitrifying activated sludge. Chemosphere, 41 (8), 12391243 (5 pages).

Litved, H., (2006). Occurrence and removal of selected organic micropollutants at mechanical, chemical and advanced wastewater treatment plants in Norway. Water Res., 40 (19), 3559-3570 (12 pages) 


\section{A. O. Ifelebuegu}

Wu, J.; He, C., (2010). Experimental and modeling investigation of sewage solids sedimentation based on particle size distribution and fractal dimension. Int. J. Environ. Sci. Tech., 7 (1), 37-46 (10 pages).

Xu, K.; Harper Jr, W. F.; Zhao, D., (2008). 17 $\alpha$-ethinyestradiol sorption to activated sludge biomass: Thermodynamic properties and reaction mechanism. Water Res., 42 (12), 3146-3152 (7 pages).
Zhang, Y.; Zhou, J. L., (2008). Occurrence and removal of endocrine disrupting chemicals in wastewater. Chemosphere, 73 (5), 848-853 (6 pages).

Zhou, H.; Huang, X.; Wang, X.; Zhi, X.; Yang, C.; Wen, X.; Wang, Q.; Tsuno, H.; Tanaka, H., (2010). Behavior of selected endocrine disrupting chemicals in three sewage treatment plants of Beijing, China. Environ. Monit. Assess., 161 (1-4), 107-121 (15 pages).

\section{AUTHOR (S) BIOSKETCHES}

Ifelebuegu, M.O., M.Sc., MEng. Senior Lecturer, Department of Geography, Environment and Disaster Management, Coventry University, Coventry, CV1 5FB, United Kingdom. Email: A.Ifelebuegu@coventry.ac.uk 